\title{
E-cadherin regulators are differentially expressed in the epithelium and stroma of keratocystic odontogenic tumors
}

\author{
Lia Pontes Arruda Porto', Jean Nunes dos Santos², Luciana Maria Pedreira Ramalho ${ }^{3}$, Andreia Leal \\ Figueiredo $^{4}$, Bráulio Carneiro Júnior ${ }^{1}$, Clarissa Araújo Gurgel ${ }^{3}$, Katiúcia Batista Silva Paiva ${ }^{5}$, Flávia Caló \\ Aquino Xavier ${ }^{2}$ \\ ${ }^{1}$ Pos-graduate Program of Dentistry and Health, School of Dentistry, Federal University of Bahia, Salvador, Brazil; ${ }^{2}$ Surgical Pathology \\ Laboratory, Department of Propaedeutics and Integrated Clinical Practicum, School of Dentistry, Federal University of Bahia, Salvador, \\ Brazil; ${ }^{3}$ Department of Propaedeutics and Integrated Clinical Practicum, School of Dentistry, Federal University of Bahia, Salvador, \\ Brazil; ${ }^{4}$ Department of Social and Pediatric Dentistry, School of Dentistry, Federal University of Bahia, Salvador, Brazil; ${ }^{5}$ Extracellular \\ Matrix Biology and Cellular Interaction Laboratory, Department of Anatomy, Institute of Biomedical Sciences, University of São Paulo, \\ São Paulo, Brazil
}

BACKGROUND: The epithelial-mesenchymal transition (EMT) is the process where cells lose their epithelial features and acquire properties of typical mesenchymal cells. The dissociation of tumor cells due to changes in cell-cell adhesion is one of the key principles of tumor invasion and EMT. Thus, the knowledge of the molecular features of EMT in keratocyst odontogenic tumor (KOT) can provide useful markers to aid in the diagnosis and prognosis and perhaps contribute to an alternative therapeutic approach as it shows an aggressive clinical behavior and high recurrence rates. This study aimed to evaluate the EMT in KOT by the immunoexpression of Ecadherin, $\mathbf{N}$-cadherin, Snail, and Slug and comparing to radicular cysts and dental follicles.

METHODS: Thirty-two KOTs, I 5 radicular cysts, and 08 dental follicles were used for immunohistochemistry, evaluating the extent, intensity, labeling pattern, cellular compartment in the epithelium and stroma, and the presence of inflammation.

RESULTS: E-cadherin was preserved in most cases of keratocystic odontogenic tumor. $\mathrm{N}$-cadherin was increased in the tumor epithelium, a result that was positively correlated with the heterogeneous and nuclear immunoexpression of Slug in the epithelium; Slug also correlated with high Snail immunoexpression. N-cadherin was positively correlated with Slug in the stroma of keratocystic odontogenic tumors.

CONCLUSIONS: The high immunoexpression of Snail and nuclear Slug in keratocystic odontogenic tumors suggests these proteins as transcription factors without necessarily participating in 'cadherin switching'. However,

Correspondence: Flávia Caló Aquino Xavier, PhD, Faculdade de Odontologia, Av. Araújo Pinho, 62, Canela 40110-150, Salvador/Bahia, Brazil. Tel: 55 (71) 3283 9029, Fax: 55 (71) 3283 8962, E-mail: f.calo@uol.com. br

Accepted for publication September 30, 2015 the knowledge of their induction of the epithelial-mesenchymal transition in odontogenic tumors is still limited.

J Oral Pathol Med (2016) 45: 302-3II

Keywords: cell adhesion; E-cadherin; epithelial-mesenchymal transition; immunohistochemistry; odontogenic tumors

\section{Introduction}

Keratocystic odontogenic tumor (KOT), previously known as odontogenic keratocyst, is a benign cystic neoplasia resulting from odontogenic epithelial remnants $(1,2)$. Its current nomenclature was suggested in 2005, when the World Health Organization (WHO) recognized its distinct clinical behavior, given its aggressive infiltrative pattern and high rate of local recurrence, and reclassified it as benign odontogenic neoplasia (3).

The epithelial-mesenchymal transition (EMT) is a complex process through which epithelial cells lose their polarity and reorganize their cytoskeleton, acquiring a mesenchymal phenotype and increased migration (4). The EMT has key roles during embryogenesis and in pathological conditions, including fibrosis and carcinogenesis $(5,6)$.

Epithelial and mesenchymal components are also known to participate in the growth regulation of odontogenic cystic lesions and tumors (7). Evidence of the involvement of the EMT in the progression of odontogenic tumors is limited, especially in KOTs. Therefore, it is essential to examine the expression of EMT-regulating proteins in those tumors, including molecules associated with the E-cadherin epithelial adhesion pathway, namely Snail and Slug, and with the expression of mesenchymal markers related to this process, including $\mathrm{N}$-cadherin, as already studied by some authors (8-12). A significant downregulation in the expression of 
cell adhesion proteins as E-cadherin in the epithelium of KOT may explain a molecular mechanism to understand initiating and development of KOTs and an alternative therapeutic approach (9). In ameloblastomas, a high rate was positive for N-cadherin, but no cases of dentigerous cyst showed positivity (10). Transcription factors as Snail and Slug probably play differential roles in mediating local invasiveness in odontogenic tumors. Specifically, it is possible that ovexpression of Snail represents the prototype transcription factor involved in inducing EMT in the ameloblastoma (12).

Thus, furthering the understanding of tumor biology should unveil the complex aspects of the interaction between tumor components that may affect the tumor's biological behavior. However, thus far, few studies examining tumor progression through the EMT that focused on cell adhesion in KOTs have been published. This promising approach might assist in defining more refined answers to the biological behavior of these tumors.

This study aimed to evaluate the EMT through the differential immunoexpression of E-cadherin and $\mathrm{N}$-cadherin associated with regulatory molecules (Snail and Slug) in the epithelial and stromal compartments of KOTs, as changes related to some proteins are apparently involved in the growth mechanism, invasion potential, and aggressiveness of KOT. For comparative purposes, radicular cysts (RCs) and dental follicles (DF) as morphologically healthy odontogenic tissue were included.

\section{Materials and methods}

\section{Biological samples}

Thirty-two samples of KOT and 15 samples of RC, embedded in paraffin, were retrospectively retrieved from the reports of the Pathological Anatomy Laboratory records of the School of Dentistry of the Federal University of Bahia (UFBA). They were diagnosed between 2003 and 2013 and obtained from either incisional or excisional biopsies from 2003 to 2013. Two pathologists (J.N.S. and F.C.A.X.) previously reviewed all KOT and RC histological slides stained with hematoxylin-eosin (HE) under an optical microscope to confirm the diagnosis. Those cases with unrepresentative tissue sample were excluded. The main clinical data as age, gender, tumor site and region, and recurrence history were also collected for KOT samples. Eight cases of DF resulting from impacted tooth extraction surgery, representing morphologically healthy tissue with odontogenic epithelial remnants, were also included. This study was approved by the Research Ethics Committee of the School of Dentistry, UFBA, under number 217.452.

\section{Immunohistochemistry reactions}

The paraffin blocks were sectioned $(3 \mu \mathrm{m})$ in a microtome, and the sections were extended on previously silanized $2 \%$ in acetone glass slides. The laboratory procedures were conducted in the Immunohistochemistry Laboratory of the School of Dentistry, UFBA, using the immunoperoxidase method. Immunohistochemistry reactions were standardized in paraffin samples of human (human skin for E-cadherin) or animal (mouse embryo for N-cadherin and mouse kidney for Snail and Slug) control tissues with known immunoreactivities to the specific immunostaining of E-cadherin, Ncadherin, and Snail and Slug proteins. The same tissues, wherein the primary antibody was replaced by non-immune serum, were used as negative external controls. The descriptions of each primary antibody, dilution, and detection system used for each protein are outlined in Table 1.

Initially, the sections were deparaffinized through immersion in xylol and were rehydrated in decreasing percentages of ethanol, followed by incubation in PBS-diluted 3\% hydrogen peroxide for $40 \mathrm{~min}$. Following antigenic exposure through immersion in $10 \mathrm{mM}$ citrate (pH 6.0) buffer solution in a steamer at $95^{\circ} \mathrm{C}$ for $20 \mathrm{~min}$, the sections were incubated for $10 \mathrm{~min}$ in Protein Block Serum-Free (K0909; Dako, Carpenteria, CA, USA) to block non-specific sites, followed by incubation with a primary antibody in a wet chamber at $4^{\circ} \mathrm{C}$ for $18 \mathrm{~h}$. Incubation with the EnVision ${ }^{\mathrm{TM}}$ Dual Link (K4061; Dako) detection system occurred for 30 min, and incubation with LSAB ${ }^{\mathrm{TM}}$ (K0690; Dako) and ADVANCE $^{\mathrm{TM}}$ (K4068; Dako) occurred in two phases lasting $30 \mathrm{~min}$ each. The reaction development was performed using 3,3'-diaminobenzidine (K3468; Dako Liquid DAB Plus, Dako), and the slides were counterstained with Mayer's hematoxylin. The sections were washed twice with PBS (pH 7.4) buffer solution supplemented with $0.1 \%$ Triton between those passages. The sections were then dehydrated, diaphanized, and mounted in Permount resin (Fisher Scientific, Fair Lawn, NJ, USA) for observation under a light microscope.

\section{Immunostaining analysis}

Protein immunoexpression was analyzed semiquantitatively and qualitatively for immunostaining extent and intensity (weak, moderate, and strong), staining pattern (homogeneous and heterogeneous), cellular compartment (nucleus, cytoplasm, and/or cell membrane), and effect of the presence of inflammation in immunostained areas (absent, non-significant, and significant) in KOTs, RCs, and DFs.

The variable immunoexpression extent was specifically categorized for each antibody analyzed: E-cadherin (11), N-cadherin (10), and Snail and Slug (12). Only the

Table 1 Types of primary antibodies, host animals, brands, catalog numbers, clones, blocking of non-specific interactions, and detection systems used in the immunohistochemistry reactions

\begin{tabular}{llllllll}
\hline Antibody & $\begin{array}{c}\text { Type of } \\
\text { antibody }\end{array}$ & $\begin{array}{c}\text { Host } \\
\text { animal }\end{array}$ & Brand & $\begin{array}{c}\text { Catalog } \\
\text { number }\end{array}$ & Clone & $\begin{array}{c}\text { Blocking of } \\
\text { non-specific } \\
\text { interactions }\end{array}$ & $\begin{array}{c}\text { Primary } \\
\text { antibody } \\
\text { dilution }\end{array}$ \\
\hline E-cadherin & Monoclonal & Mouse & Dako & M3612 & NCH38 & No blocking & $1: 50$ \\
N-cadherin & Polyclonal & Rabbit & Abcam & ab12221 & - & Blocking solution & $1: 250$ \\
Snail & Polyclonal & Goat & Abcam & ab53519 & - & Blocking solution & $1: 50$ \\
Slug & Polyclonal & Rabbit & Abcam & ab27568 & - & No blocking & LSAB \\
\hline
\end{tabular}


immunostaining of dental follicles was qualitatively defined as positive or negative given the sample representativeness. The variables extent, intensity, and immunoexpression pattern were analyzed in the epithelium and/or stroma depending on the antibody.

\section{Statistical analysis}

All data recorded were tabulated and submitted to statistical analysis, with a 95\% confidence interval, using Statistical Package for the Social Sciences (SPSS, Inc., Chicago, IL, USA) version 13.0. A $P$ value $<0.05$ was considered significant. The association of antibody expression between groups (KOT, RC, and DF), clinical data, and comparisons of the extent of $\mathrm{N}$-cadherin and Snail and Slug antibody staining in the epithelium and stroma were assessed using Fisher's exact test. Spearman's rank correlation coefficient was used for the correlation between the immunostaining extent of antibodies with each other in KOTs.

\section{Results}

Clinical date of 24 patients with KOT demonstrated ages ranging from eight to 73 years (mean age 32.33, $\mathrm{SD}=17: 58)$. The gender distribution was higher in males than females (16:8). The mandible, predominantly the posterior region, was in fact the most affected site. Twenty cases had the first occurrence of the disease, and three cases were tumoral recurrence (Table 2). There was no statistically significant association between age, gender, recurrence, and the extent of immunostaining of proteins $(P>0.05)$. However, it was noted that the following: (i) cases exclusively in the posterior region had preserved E-cadherin $(>50 \%)$ compared to cases with anterior mandible involvement $(P=0.046)$; (ii) mandibular KOT expressed significantly $\mathrm{N}$ cadherin and Slug in epithelium in a high extent (scores 3 and 4) immunostaining (Fisher's exact test $P=0.000$ and $P=0.005$, respectively); and (iii) when lesion was located in the mandible and maxilla simultaneously had no expression of $\mathrm{N}$-cadherin in stroma $(P=0.006)$.

Differential protein immunoexpression in $K O T, R C$, and DF E-cadherin

The analysis of E-cadherin immunoexpression in the three study groups is outlined in Table 2. Most KOTs $(62.5 \%)$

Table 2 Main clinical data of keratocystic odontogenic tumor cases in the studied sample

\begin{tabular}{llrr}
\hline \multirow{2}{*}{ Clinical data } & & \multicolumn{2}{c}{ KOT } \\
\cline { 3 - 4 } & Features & $\mathrm{N}$ & $\%$ \\
\hline Age & $\leq 28$ years & 13 & 5.1 \\
& $>28$ years & 11 & 45.8 \\
Gender & Male & 8 & 33.3 \\
& Female & 16 & 66.6 \\
Tumor site & Maxilla & 0 & 0 \\
& Mandible & 22 & 91.6 \\
Tumor region & Maxilla and mandible & 2 & 8.3 \\
& Anterior & 2 & 12.5 \\
\multirow{2}{*}{ Recurrence } & Posterior & 11 & 68.7 \\
& Anterior and posterior & 3 & 18.7 \\
& No & 12 & 80 \\
& Yes & 3 & 20 \\
\hline
\end{tabular}

showed preserved immunoexpression. All of the eight cases of DF showed positive immunoreactivity. Immunostaining was detected in the plasma membrane of the epithelial lining, odontogenic epithelial remains, and a focal area of the reduced epithelium of the enamel organ (Fig. 1A-I). A comparison between the three study groups revealed a significant difference in the marked effect of inflammation on E-cadherin immunoexpression in RCs $(P=0.000$, Table 3).

\section{$\mathrm{N}$-cadherin}

$\mathrm{N}$-cadherin immunoexpression was detected in both the plasma membrane and the cytoplasm and/or nucleus in the epithelium and the stroma/capsule (Fig. 1J-O), ranging considerably from case to case and showing a rather granular appearance (Fig. 1M). The eight cases of DF showed positive $\mathrm{N}$-cadherin immunoexpression in the epithelium. Stronger combined immunostaining in the membrane and cytoplasm was observed in lesions (KOTs and RCs), with predominant cytoplasmic immunostaining alone in DF, which was statistically significant $(P=0.001$, Table 4). A significant difference was also observed regarding the marked effect of inflammation on the $\mathrm{N}$ cadherin immunoexpression of RCs $(P=0.000$, Table 4) when analyzing inflammation in the three groups.

A statistically significant difference $(P=0.004)$ was observed when comparing the $\mathrm{N}$-cadherin immunoexpression extent in the epithelium with that in the stroma of KOTs, with the epithelium showing stronger N-cadherin immunoexpression than the stroma.

Snail

The KOT, RC, and DF cases showed high nuclear and/or cytoplasmic Snail immunoexpression in the epithelium and/ or stroma (Fig. 2A-F, Table 5). Endothelial cells and fibroblasts were immunostained in the stroma (Fig. 2A-F).

No variable analyzed in the epithelium exhibited statistically significant results when the three study groups were compared $(P>0.05$; Table 5). Statistically significant differences were only assessed in the stroma when analyzing the extent $(P=0.031)$ and the presence of inflammation changing the immunoreactivity of Snail $(P=0.000)$ (Table 4). No statistically significant difference $(P=0.543)$ occurred when comparing the Snail immunostaining extent in the epithelium with that in the stroma of KOTs.

Slug

The KOT, RC, and DF cases showed nuclear and/or cytoplasmic Slug immunostaining in the epithelium and/or stroma (Fig. 2G-L, Table 5). Immunostaining was detected in the keratin layer in two cases of KOT (Fig. 2G).

Statistically significant differences were identified in intensity $(P=0.046)$, with a predominance of moderate and strong intensity in KOTs and intense expression in DFs, with a heterogeneous pattern in KOTs $(P=0.011)$ characterized by staining in the nuclear/cytoplasmic cellular compartment and exclusively cytoplasmic staining in DFs $(P=0.001$; Table 5) when the three groups were compared in terms of epithelial staining. A statistically significant difference was only assessed in the stroma when analyzing 


\section{KOT}
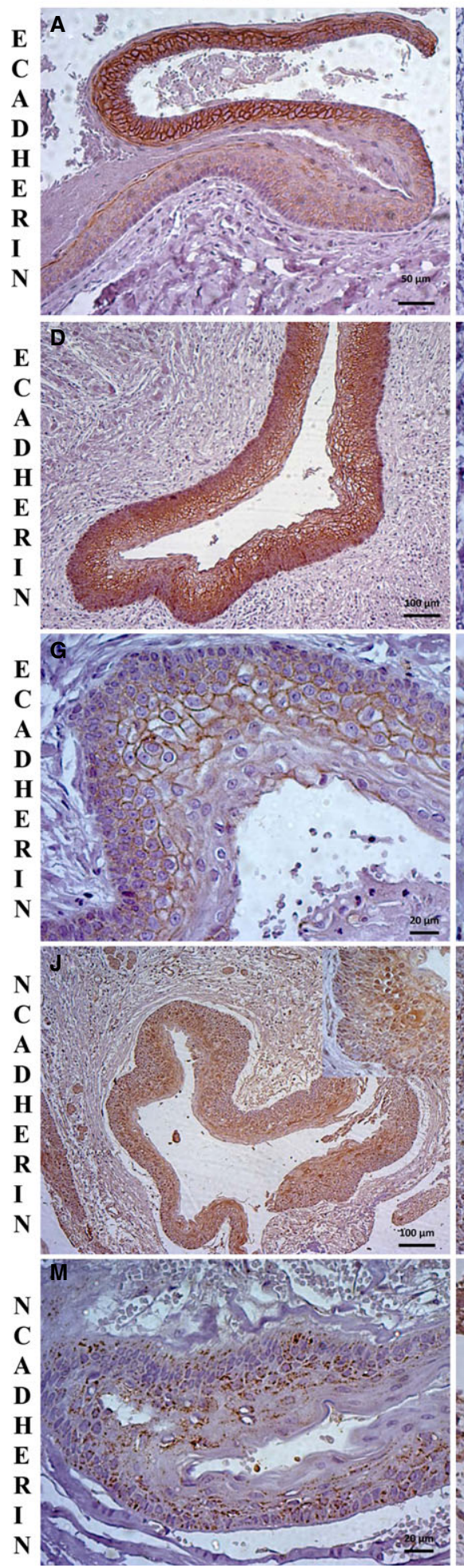

RC
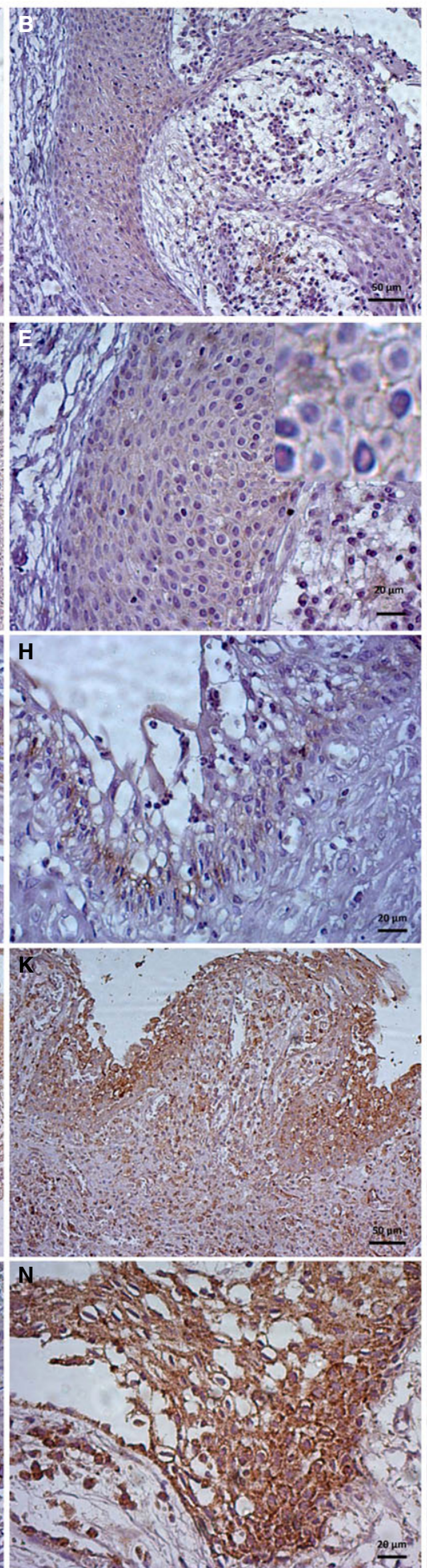

DF

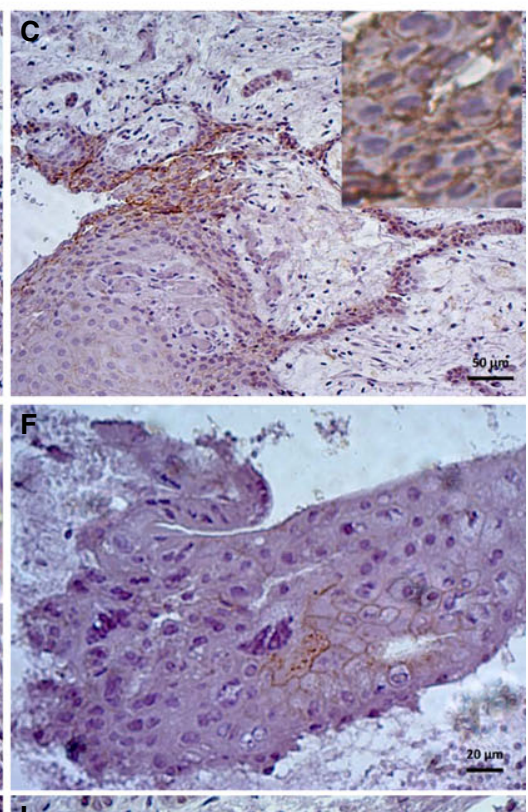

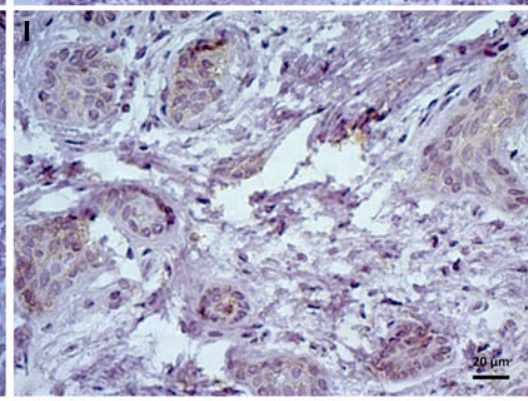
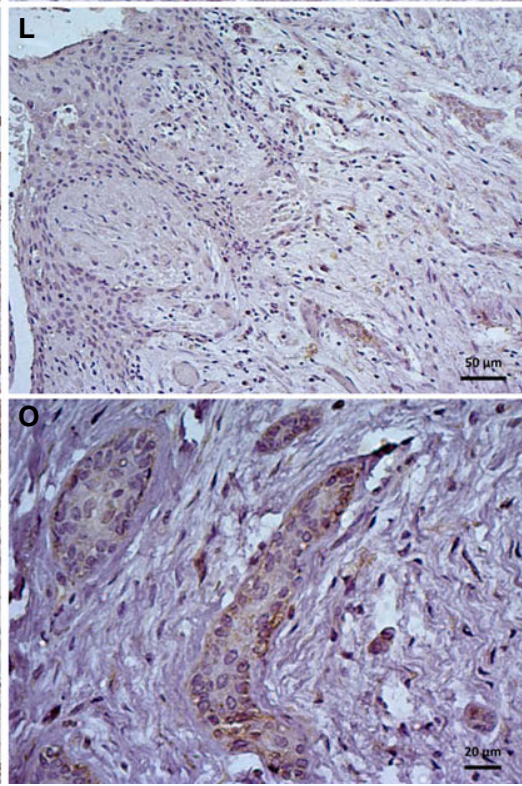

Figure 1 Immunoexpression of E-cadherin and N-cadherin in keratocystic odontogenic tumors (KOTs), radicular cysts (RCs), and dental follicles (DFs). Ecadherin shows moderate (A) and intense (A and D) immunoexpression in KOTs, with a membranous pattern (G) primarily distributed in the suprabasal stratum (A and G) or in all stratum (D). E-cadherin shows weak (B and E) immunostaining in RCs, with a membranous pattern (E, insert) in all stratum (E) or in the suprabasal stratum (H). E-cadherin shows focal immunostaining in the lining epithelium (C, insert) and in the reduced epithelium of the enamel organ (F) in DFs. N-cadherin shows intense (J) and moderate (M) immunostaining with membranous, cytoplasmic, or nuclear patterns (J, insert) distributed in all stratum $(\mathrm{J})$ and sometimes with a granular appearance $(\mathrm{M})$ in the KOT epithelium. The stroma shows immunostaining $(\mathrm{J})$. N-cadherin shows moderate $(\mathrm{K})$ and intense $(\mathrm{N})$ immunostaining with a membranous/cytoplasmic pattern $(\mathrm{N})$ in the RC epithelium and in inflammatory cells $(\mathrm{K})$. N-cadherin is noticeably absent from the lining epithelium (L), with weak membranous/cytoplasmic immunostaining in the odontogenic epithelium (O), in DFs. The scales indicate $20 \mu \mathrm{m}(\mathrm{E}, \mathrm{F}, \mathrm{G}, \mathrm{H}, \mathrm{I}, \mathrm{M}, \mathrm{N}$ and $\mathrm{O}), 50 \mu \mathrm{m}(\mathrm{A}, \mathrm{B}, \mathrm{C}, \mathrm{K}$, and $\mathrm{L})$ and $100 \mu \mathrm{m}(\mathrm{D}$ and $\mathrm{J})$. 
Table 3 E-cadherin immunoexpression characterizations in the KOT, RC, and DF lesions

\begin{tabular}{|c|c|c|c|c|c|c|c|}
\hline \multirow[b]{2}{*}{ E-cadherin } & \multicolumn{2}{|c|}{ KOT } & \multicolumn{2}{|c|}{$R C$} & \multicolumn{2}{|c|}{$D F$} & \multirow[b]{2}{*}{$\mathrm{P}$} \\
\hline & $\mathrm{n}$ & $\%$ & $\mathrm{n}$ & $\%$ & $\mathrm{n}$ & $\%$ & \\
\hline \multicolumn{8}{|l|}{ Extent } \\
\hline Absent & 2 & 6.3 & 2 & 13.3 & - & - & 0.291 \\
\hline$<20 \%$ & 4 & 12.5 & 4 & 26.7 & - & - & \\
\hline $20-50 \%$ & 6 & 18.8 & 4 & 26.7 & - & - & \\
\hline$>50 \%$ & 20 & 62.5 & 5 & 33.3 & - & - & \\
\hline \multicolumn{8}{|l|}{ Intensity } \\
\hline Absent & 2 & 6.3 & 2 & 13.3 & 0 & 0 & 0.144 \\
\hline Weak & 6 & 18.8 & 4 & 26.7 & 0 & 0 & \\
\hline Moderate & 12 & 37.5 & 7 & 46.7 & 2 & 25 & \\
\hline Strong & 12 & 37.5 & 2 & 13.3 & 6 & 75 & \\
\hline \multicolumn{8}{|l|}{ Pattern } \\
\hline Homogeneous & 25 & 78.1 & 9 & 60 & - & - & 0.295 \\
\hline Heterogeneous & 7 & 21.9 & 6 & 40 & - & - & \\
\hline \multicolumn{8}{|l|}{ Inflammation } \\
\hline Absent & 17 & 53.1 & 0 & 0 & 6 & 75 & $0.000 *$ \\
\hline Non-significant & 8 & 25 & 4 & 26.7 & 2 & 25 & \\
\hline Significant & 7 & 21.9 & 11 & 73.3 & 0 & 0 & \\
\hline
\end{tabular}

*Fisher's exact test, $P<0.05$.

intensity $(P=0.023)$, with all cases of KOTs with moderate or strong intensity (Table 5). The presence of inflammation markedly changed Slug immunostaining in RCs $(P=0.000$; Table 5). No statistically significant difference was assessed $(P=0.153)$ when comparing the extent of Slug immunostaining in the epithelium with that in the stroma of KOTs.

\section{Correlations between protein immunoexpression levels in KOTs}

The following statistically significant and positive correlations were observed when assessing the correlations existing between the study proteins in KOTs, either through their epithelial or stromal expression: N-cad (epithelium) X Slug (epithelium; $P=0.024,0.328$ Spearman's rank correlation coefficient); N-cad (stroma) X Slug (stroma; $P=0.019$, 0.346 Spearman's rank correlation coefficient); and Snail (epithelium) X Slug (epithelium; $P=0.021,0.335$ Spearman's rank correlation coefficient).

\section{Discussion}

Our results showed epithelial E-cadherin immunostaining and epithelial/stromal N-cadherin, Snail, and Slug immunostaining in KOTs, without an apparent loss of Ecadherin immunoexpression in most cases. The results were not different from those detected in RCs. However, the expression levels of all proteins were markedly affected by inflammation in the RCs and that characteristic enables one to confidently differentiate KOTs and DFs from RCs. Ncadherin expression was increased in the tumor epithelium compared to the stroma, specially in mandible tumors, a result that was correlated with the positive expression of Slug in the epithelium; in turn, Slug expression was correlated with positive Snail expression. N-cadherin was positively correlated with Slug in the stroma of KOTs. To our knowledge, this study is the first to address the simultaneous involvement of these markers in KOTs.
Adhesion molecules, including E-cadherin, have been studied in odontogenic tumors with the goal of understanding their roles in neoplastic progression (13-17), cell differentiation, and the development and capacity of tumor invasion $(9-11,18)$. Although decreased E-cadherin immunoexpression might explain the invasive growth of KOTs (9), that evidence was not confirmed in the present study because $62.5 \%$ of KOT cases showed preserved E-cadherin immunoexpression. Similar results were reported by Kusafuka et al. (10) and Mello et al. (11). The latter authors suggested that a high level of cell adhesion exists between the parenchymal cells of this tumor.

Some E-cadherin immunoexpression difference presumably exists between the study lesions, based on the hypothesis that the EMT is involved in the progression of KOTs, as shown by Hakim et al. (9), who observed significant decreases in the membrane expression levels of $\beta$-catenin and E-cadherin in all 18 samples of sporadic and syndromic KOTs, especially in the suprabasal layer, while the eight dentigerous cysts conversely showed preserved immunostaining from the basal membrane of the epithelial layer to the luminal surface. However, this study detected no statistically significant difference when comparing the extent of E-cadherin immunoexpression between KOT, RC, and FOL, although 37.6\% of KOTs showed reduced Ecadherin immunoexpression. Alves Pereira et al. (19) also failed to observe differences in E-cadherin immunoexpression in ameloblastomas and tooth germs because all cases showed positive E-cadherin immunoexpression. Conversely, Mello et al. (11) noted that all 18 cases of KOT and four cases of calcifying cystic odontogenic tumor showed significantly stronger E-cadherin immunoexpression than that observed in 20 ameloblastomas, suggesting its key role in cell adhesion mediation in odontogenic tumors.

Cadherin switching, represented by increased N-cadherin expression and concomitant low E-cadherin expression, is reportedly a crucial characteristic of the EMT (20). In the present study, high $\mathrm{N}$-cadherin expression was shown in the epithelium of KOTs and in RCs. N-cadherin was expressed at higher levels in the tumor epithelium than in the stroma in KOTs. Only one study was identified in which N-cadherin expression in KOTs was assessed: Kusafuka et al. (10) identified four cases of KOT $(40.0 \%)$ positive for $\mathrm{N}$ cadherin expression but with negative immunoreactivity in all seven dentigerous cysts that were evaluated. Therefore, according to the results from the present study, $\mathrm{N}$-cadherin is apparently involved in KOT progression and may operate in EMT signaling through interactions with other regulators. Furthermore, the presence of inflammation contributed to increased N-cadherin expression in RCs.

No studies on odontogenic tumors evaluating the differential expression patterns of $\mathrm{N}$-cadherin in cellular compartments have been reported. The $\mathrm{N}$-cadherin staining pattern in this study was similar to that observed in head and neck carcinomas $(17,21)$ : most KOTs and RCs showed membranous and cytoplasmic staining, and most DFs showed only cytoplasmic staining. However, it is noteworthy that no RC or DF showed nuclear immunostaining, which was significantly detected in $33.4 \%$ of KOTs. Based on their study results, DI Domenico et al. (22) hypothesized that the $\mathrm{N}$-cadherin in cellular compartments may be a 
Table 4 N-cadherin immunoexpression characterizations in $\mathrm{KOT}, \mathrm{RC}$, and $\mathrm{DF}$ lesions

\begin{tabular}{|c|c|c|c|c|c|c|c|}
\hline \multirow[b]{2}{*}{$N$-cadherin } & \multicolumn{2}{|c|}{ KOT } & \multicolumn{2}{|c|}{$R C$} & \multicolumn{2}{|c|}{$D F$} & \multirow[b]{2}{*}{$\mathrm{P}$} \\
\hline & $\mathrm{n}$ & $\%$ & $\mathrm{n}$ & $\%$ & $\mathrm{n}$ & $\%$ & \\
\hline \multicolumn{8}{|l|}{ Epithelial extent } \\
\hline Absent & 2 & 6.3 & 0 & 0 & - & - & 0.073 \\
\hline$<10 \%$ & 1 & 3.1 & 2 & 13.3 & - & - & \\
\hline $10-20 \%$ & 0 & 0 & 0 & 0 & - & - & \\
\hline$>20 \%$ & 8 & 25 & 0 & 0 & - & - & \\
\hline$>50 \%$ & 21 & 65.6 & 13 & 86.7 & - & - & \\
\hline \multicolumn{8}{|l|}{ Stromal extent } \\
\hline Absent & 4 & 12.9 & 1 & 6.7 & - & - & 0.803 \\
\hline$<10 \%$ & 10 & 32.3 & 6 & 40 & - & - & \\
\hline $10-20 \%$ & 3 & 9.7 & 2 & 13.3 & - & - & \\
\hline$>20 \%$ & 8 & 25.8 & 2 & 13.3 & - & - & \\
\hline$>50 \%$ & 6 & 19.4 & 4 & 26.7 & - & - & \\
\hline \multicolumn{8}{|l|}{ Epithelial intensity } \\
\hline Absent & 2 & 6.3 & 0 & 0 & 0 & 0 & 0.710 \\
\hline Weak & 5 & 15.6 & 2 & 13.3 & 1 & 12.5 & \\
\hline Moderate & 12 & 37.5 & 8 & 53.3 & 2 & 25 & \\
\hline Strong & 13 & 40.6 & 5 & 33.3 & 5 & 62.5 & \\
\hline \multicolumn{8}{|l|}{ Stromal intensity } \\
\hline Absent & 4 & 12.9 & 1 & 6.7 & 0 & 0 & 0.542 \\
\hline Weak & 8 & 25.8 & 3 & 20 & 3 & 50 & \\
\hline Moderate & 10 & 32.3 & 3 & 20 & 1 & 16.7 & \\
\hline Strong & 9 & 29 & 8 & 53.3 & 2 & 33.3 & \\
\hline \multicolumn{8}{|l|}{ Epithelial pattern } \\
\hline Homogeneous & 16 & 50 & 7 & 46.7 & - & - & 1.000 \\
\hline Heterogeneous & 16 & 50 & 8 & 53.3 & - & - & \\
\hline \multicolumn{8}{|l|}{ Stromal pattern } \\
\hline Homogeneous & 10 & 32.3 & 6 & 40 & - & - & 0.744 \\
\hline Heterogeneous & 21 & 67.7 & 9 & 60 & - & - & \\
\hline \multicolumn{8}{|l|}{ Inflammation } \\
\hline Absent & 8 & 26.7 & 0 & 0 & 7 & 87.5 & $0.000 *$ \\
\hline Non-significant & 16 & 53.3 & 4 & 26.7 & 1 & 12.5 & \\
\hline Significant & 6 & 20 & 11 & 73.3 & 0 & 0 & \\
\hline \multicolumn{8}{|l|}{ Cellular compartment } \\
\hline Membrane & 3 & 10 & 0 & 0 & 0 & 0 & $0.001 *$ \\
\hline Cytoplasm & 2 & 6.7 & 4 & 26.7 & 6 & 75 & \\
\hline Membrane + Cytoplasm & 15 & 50 & 11 & 73.3 & 2 & 25 & \\
\hline Cytoplasm + nucleus & 5 & 16.7 & 0 & 0 & 0 & 0 & \\
\hline $\begin{array}{l}\text { Membrane + Cytoplasm } \\
+ \text { nucleus }\end{array}$ & 5 & 16.7 & 0 & 0 & 0 & 0 & \\
\hline
\end{tabular}

*Fisher's exact test, $P<0.05$. 

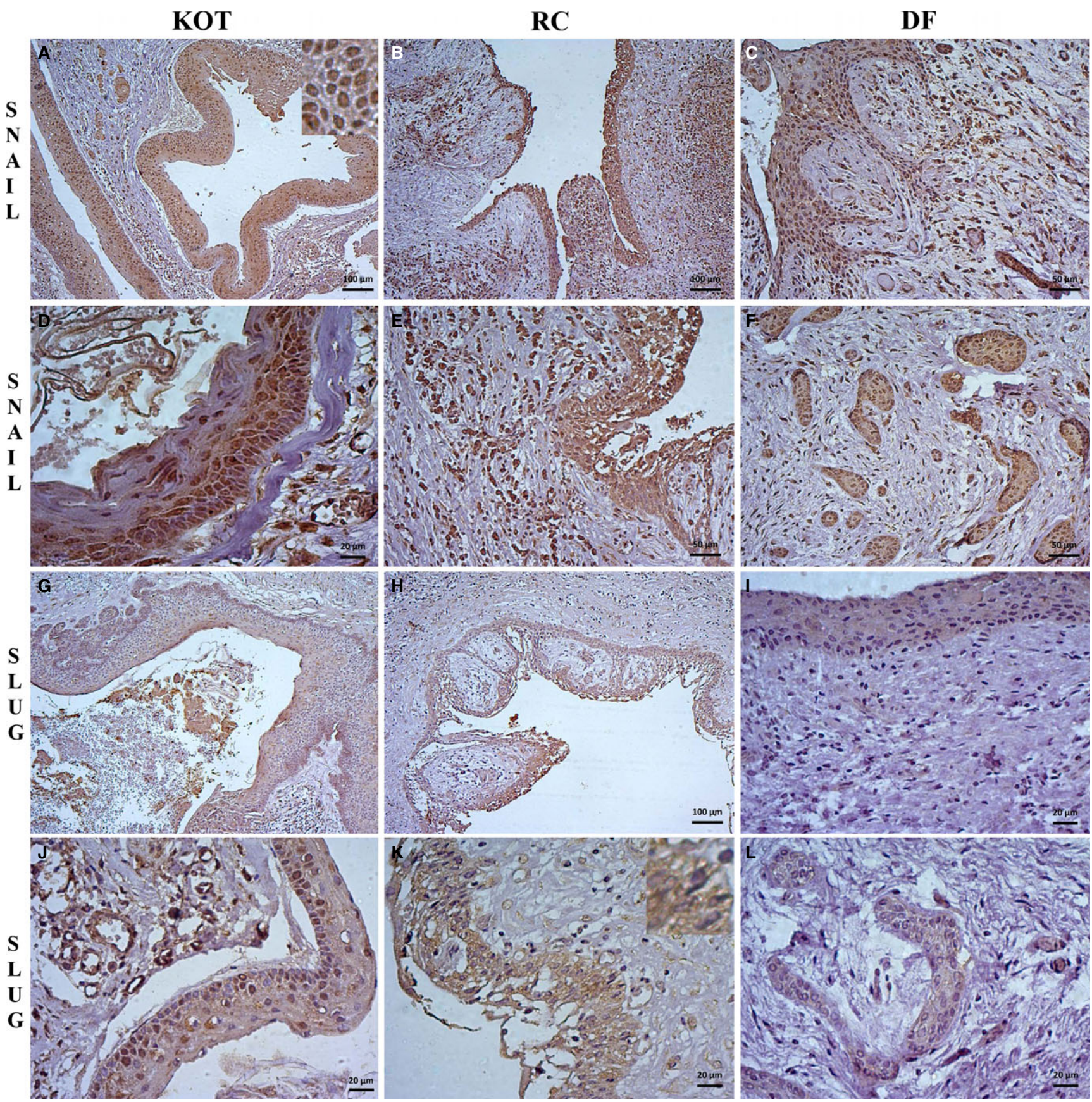

Figure 2 Immunoexpression of Snail and Slug in keratocystic odontogenic tumors (KOTs), radicular cysts (RCs), and dental follicles (DFs). Snail shows intense immunostaining in nuclear and cytoplasmic (A, insert, and D) patterns distributed in all epithelial stratum (A and D) in KOTs. The stroma shows immunostained fibroblasts and endothelial cells. Snail also shows intense immunostaining (B and E) in nuclear and cytoplasmic patterns (E) distributed in all epithelial stratum (B and E) and in inflammatory cells (B and E) in RCs. Snail shows immunostaining in the lining epithelium (C) and in the reduced epithelium of the enamel organ (F) in DFs. Slug shows moderate immunostaining ( $G$ and $J$ ) in a heterogeneous cytoplasmic pattern distributed in all stratum $(\mathrm{J})$ in the KOT epithelium. Immunostaining of fibroblasts and endothelial cells is observed (G and J). Slug shows moderate $(\mathrm{H}$ and $\mathrm{K})$ immunostaining in a homogeneous cytoplasmic pattern distributed in all stratum (K, insert) in the RC epithelium. DFs show weak cytoplasmic immunostaining of Slug in the lining epithelium (I) and odontogenic epithelium (L). The scales indicate $20 \mu \mathrm{m}(\mathrm{D}, \mathrm{I}, \mathrm{J}, \mathrm{K}$, and L), $50 \mu \mathrm{m}(\mathrm{C}, \mathrm{E}$, and F), and $100 \mu \mathrm{m}(\mathrm{A}, \mathrm{B}, \mathrm{G}$, and H).

squamous cell carcinoma, which may explain the increased expression in RCs in the present study.

Snail and Slug are not equivalent despite their similar structural conformations, as specific combinations of zinc fingers (ZF1/ZF2 in Snail1 and ZF3/ZF4 in Snail2) are necessary for complete repression activity. Therefore, the proteins may play non-equivalent roles in gene repression,
DNA binding conformation, and the capacity to induce the EMT (28). Depending on the tissue analyzed, Slug has indeed shown a different behavior from Snail. In the present study, no differences in Slug immunoexpression extent were assessed in KOTs, RCs, and DFs. However, a statistically significant result was detected when analyzing the expression intensities in the epithelium and stroma. DFs intensely 
Table 5 Snail and Slug immunoexpression characterizations in KOT, RC, and DF lesions

\begin{tabular}{|c|c|c|c|c|c|c|c|c|c|c|c|c|c|c|}
\hline & \multicolumn{6}{|c|}{ Snail } & \multirow[b]{3}{*}{$\mathrm{P}$} & \multicolumn{6}{|c|}{ Slug } & \multirow[b]{3}{*}{$\mathrm{P}$} \\
\hline & \multicolumn{2}{|c|}{ KOT } & \multicolumn{2}{|c|}{$R C$} & \multicolumn{2}{|c|}{$D F$} & & \multicolumn{2}{|c|}{ KOT } & \multicolumn{2}{|c|}{$R C$} & \multicolumn{2}{|c|}{$D F$} & \\
\hline & $\mathrm{n}$ & $\%$ & $\mathrm{n}$ & $\%$ & $\mathrm{n}$ & $\%$ & & $\mathrm{n}$ & $\%$ & $\mathrm{n}$ & $\%$ & $\mathrm{n}$ & $\%$ & \\
\hline \multicolumn{15}{|l|}{ Epithelial extent } \\
\hline Absent & 1 & 3.1 & 0 & 0 & - & - & \multirow[t]{4}{*}{0.681} & 1 & 3.1 & 0 & 0 & - & - & \multirow{4}{*}{0.690} \\
\hline$<25 \%$ & 1 & 3.1 & 1 & 6.7 & - & - & & 8 & 25 & 2 & 13.3 & - & - & \\
\hline $25-50 \%$ & 5 & 15.6 & 1 & 6.7 & - & - & & 8 & 25 & 5 & 33.3 & - & - & \\
\hline$>50 \%$ & 25 & 78.1 & 13 & 86.7 & - & - & & 15 & 46.9 & 8 & 53.3 & - & - & \\
\hline \multicolumn{15}{|l|}{ Stromal extent } \\
\hline Absent & 0 & 0 & 0 & 0 & - & - & \multirow[t]{4}{*}{$0.031 *$} & 0 & 0 & 0 & 0 & - & - & \multirow[t]{4}{*}{0.515} \\
\hline$<25 \%$ & 10 & 33.3 & 1 & 6.7 & - & - & & 3 & 9.7 & 3 & 20 & - & - & \\
\hline $25-50 \%$ & 10 & 33.3 & 3 & 20 & - & - & & 11 & 35.5 & 6 & 40 & - & - & \\
\hline$>50 \%$ & 10 & 33.3 & 11 & 73.3 & - & - & & 17 & 54.8 & 6 & 40 & - & - & \\
\hline \multicolumn{15}{|l|}{ Epithelial intensity } \\
\hline Absent & 1 & 3.1 & 0 & 0 & 0 & 0 & \multirow[t]{4}{*}{0.839} & 1 & 3.1 & 0 & 0 & 0 & 0 & \multirow[t]{4}{*}{$0.046^{*}$} \\
\hline Weak & 1 & 3.1 & 1 & 6.7 & 0 & 0 & & 4 & 12.5 & 6 & 40 & 1 & 12.5 & \\
\hline Moderate & 8 & 25 & 6 & 40 & 2 & 25 & & 14 & 43.8 & 3 & 20 & 0 & 0 & \\
\hline Strong & 22 & 68.8 & 8 & 53.3 & 6 & 75 & & 13 & 40.6 & 6 & 40 & 7 & 87.5 & \\
\hline \multicolumn{15}{|l|}{ Stromal intensity } \\
\hline Absent & 0 & 0 & 0 & 0 & 0 & 0 & \multirow[t]{4}{*}{0.629} & 0 & 0 & 0 & 0 & 0 & 0 & \multirow[t]{4}{*}{$0.023^{*}$} \\
\hline Weak & 0 & 0 & 0 & 0 & 0 & 0 & & 0 & 0 & 3 & 20 & 3 & 37.5 & \\
\hline Moderate & 3 & 10 & 1 & 6.7 & 0 & 0 & & 13 & 41.9 & 5 & 33.3 & 1 & 12.5 & \\
\hline Strong & 27 & 90 & 14 & 93.3 & 8 & 100 & & 18 & 58.1 & 7 & 46.7 & 4 & 50 & \\
\hline \multicolumn{15}{|l|}{ Epithelial pattern } \\
\hline Homogeneous & 24 & 77.4 & 13 & 86.7 & - & - & \multirow[t]{3}{*}{0.696} & 8 & 25.8 & 10 & 66.7 & - & - & \multirow[t]{3}{*}{$0.011 *$} \\
\hline Heterogeneous & 7 & 22.6 & 2 & 13.3 & - & - & & 23 & 74.2 & 5 & 33.3 & - & - & \\
\hline Inflammation & & & & & & & & & & & & & & \\
\hline Absent & 4 & 13.3 & 0 & 0 & 7 & 87.5 & $0.000 *$ & 6 & 19.4 & 0 & 0 & 5 & 62.5 & $0.000 *$ \\
\hline Non-significant & 13 & 43.3 & 0 & 0 & 0 & 0 & & 18 & 58.1 & 2 & 13.3 & 2 & 25 & \\
\hline Significant & 13 & 43.3 & 15 & 100 & 1 & 12.5 & & 7 & 22.6 & 13 & 86.7 & 1 & 12.5 & \\
\hline Cellular compartment & & & & & & & & & & & & & & \\
\hline Nucleus & 15 & 48.4 & 7 & 46.7 & 5 & 62.5 & 0.441 & 4 & 12.5 & 0 & 0 & 0 & 0 & $0.001 *$ \\
\hline Cytoplasm & 3 & 9.7 & 1 & 6.7 & 2 & 25 & & 7 & 21.9 & 9 & 60 & 8 & 100 & \\
\hline Nucleus + cytoplasm & 13 & 41.9 & 7 & 46.7 & 1 & 12.5 & & 21 & 65.6 & 6 & 40 & 0 & 0 & \\
\hline
\end{tabular}

*Fisher's exact test, $P<0.05$.

expressed Slug in the epithelium, while all KOTs showed moderate or intense expression in the stroma, in contrast to RCs and DFs, which were well distributed among the categories.

In the present study, epithelial Slug immunostaining showed a rather heterogeneous distribution pattern in KOTs (74.2\%), unlike the homogeneity observed in RCs (66.7\%). A similar Slug expression pattern was observed in 64 ameloblastomas evaluated by Siar and $\mathrm{Ng}$ (12). However, no studies assessing Slug expression in KOTs have been reported. Thus, the heterogeneity detected might be specific to tumor tissues, which was not observed in the inflammatory cystic lesion in this study.

Regarding the protein's role as a transcription factor, several lines of evidence indicate that the nuclear forms are functionally active molecules, whereas the forms expressed in the cytoplasm are phosphorylated and functionally inactive (24, 29). Most KOTs showed notable nuclear staining in the present study, unlike the mainly cytoplasmic staining in RCs and DFs, which would suggest greater Slug activity as a transcription factor in KOTs. Different results were reported by Siar and $\mathrm{Ng}$ (12), who observed a predominantly cytoplasmic rather than nuclear Slug staining pattern in ameloblastomas and a predominantly nuclear Snail staining pattern, concluding that the transcription factors play different roles in EMT induction in ameloblas- tomas and that Snail may be the key repressor involved in this process. The results of the present study suggest that the process is apparently reverse in the case of KOTs, with the Slug protein playing the predominant role.

The EMT is characterized by the downregulation of epithelial markers and the upregulation of mesenchymal markers (30-32). In the present study, we observed a correlation between Slug and N-cadherin expression. Indeed, Snail and Slug have either direct or indirect effects on genes other than E-cadherin (28). Thus, the involvement of Slug in the EMT in KOTs may regulate $\mathrm{N}$-cadherin expression because we detected positive and statistically significant correlations between Slug and N-cadherin expression in the epithelium and stroma. The same correlation was reported by Zhang et al. (33) in samples from 119 primary head and neck carcinomas, with Slug expression levels negatively correlated with E-cadherin and positively correlated with $\mathrm{N}$-cadherin expression. However, no evidence has shown that Slug signaling is involved in the direct regulation of $\mathrm{N}$-cadherin. Therefore, further research studies involving functional assays in odontogenic tumors are required to clarify that correlation.

The increased expression of the transcription factors Snail and Slug mostly repressed E-cadherin function; they are considered key molecules in the EMT, with significant relevance in the progression of different tumors $(23,25,34)$. 
Although an inverse correlation between the expression of E-cadherin and Snail/Slug was not detected in the KOTs of the present study, a positive correlation between Snail and Slug expression was observed in the epithelium of KOTs. That result indicates how much these factors are interconnected, despite exhibiting non-equivalent roles in epithelial promoter repression, DNA binding, and the capacity to induce EMT (28). Siar and Ng (12) assessed inverse relationships between Snail and Slug in the epithelium of ameloblastomas with low Slug expression, suggesting a limited role of Slug in EMT induction in this neoplasia. The reasons for these different patterns of expression between Snail and Slug are not clear, although new evidence suggests that these transcription repressors may operate either alone or together $(35,36)$.

Inflammation causes structural tissue changes (37) and functional alterations in KOTs, mainly resulting from the effect of inflammatory cells on epithelial proliferative activity (38-40) and cytokeratin expression (41) and with a smaller impact on stromal vascularization (37). Inflammation significantly affected the immunoreactivity of the study proteins in most RCs.

Protein interactions in different tissue compartments are crucial for the EMT process. In this study, in KOTs, epithelial $\mathrm{N}$-cadherin expression was correlated with positive epithelial Slug expression, which, in turn, was correlated with positive Snail expression. N-cadherin expression was positively correlated with Slug in the stroma of KOTs. In another study, E-cadherin expression was decreased in Snail-induced cell cultures, while the expression levels of the mesenchymal markers N-cadherin and Vimentin were increased (42). Conversely, Gasparotto et al. (43) noted that the expression levels of Twist and Slug were positively correlated with the increased expression of mesenchymal markers, including $\mathrm{N}$ cadherin, and that the upregulation of these mesenchymal markers was not necessarily associated with the loss of Ecadherin expression, suggesting that the activation of a mesenchymal factor may be at least partly unrelated to the transcriptional downregulation of E-cadherin.

In conclusion, we have shown that the E-cadherin, Ncadherin, Snail, and Slug proteins are differentially expressed in the epithelium and stroma of KOTs and that the immunoexpression profile of E-cadherin was preserved in KOTs. No significant differences in protein expression occurred between KOTs, RCs, and DFs. However, protein immunoreactivity was noticeably markedly affected by inflammation in RCs. An N-cadherin expression gain occurred in the epithelium of KOTs compared to the stroma, which was correlated with Slug upregulation in the epithelium. This upregulation was likewise correlated with Snail upregulation. Furthermore, N-cadherin was positively correlated with Slug in the stroma of KOTs. The increased expression of Snail and the heterogeneous and nuclear expression pattern of Slug in KOTs suggest that these proteins are putative transcription factors in that type of odontogenic tumor, without necessarily being involved in cadherin switching. However, knowledge of the actual involvement of E-cadherin, N-cadherin, Snail, and Slug in EMT signaling in KOTs is still limited and requires further studies to define the role of each marker and their combined actions in odontogenic tumors.

\section{References}

1. Gomes CC, Gomez RS. Odontogenic keratocyst: a benign cystic neoplasm? Oral Oncol 2007; 43: 619-20.

2. Habibi A, Saghravanian N, Habibi M, Mellati E, Habibi M. Keratocystic odontogenic tumor: a 10-year retrospective study of 83 cases in an Iranian population. J Oral Sci 2007; 49: 22935 .

3. Philipsen HP. Odontogenic tumors. In: Barnes L, Eveson JW, Reichart P, Sidransky D, eds. World health organization classification of tumours: pathology and genetics of head and neck tumours. Lyon: IARC Press, 2005; 306-7.

4. Huber MA, Kraut N, Beug H. Molecular requirements for epithelial-mesenchymal transition during tumor progression. Curr Opin Cell Biol 2005; 17: 548-58.

5. Iwano M, Plieth D, Danoff TM, Xue C, Okada H, Neilson EG. Evidence that fibroblasts derive from epithelium during tissue fibrosis. J Clin Invest 2002; 110: 341-50.

6. Kang Y, Massagué J. Epithelial-mesenchymal transitions: twist in development and metastasis. Cell 2004; 118: 277-9.

7. Pinheiro JJ, Freitas VM, Moretti AI, Jorge AG, Jaeger RG. Local invasiveness of ameloblastoma. Role played by matrix metalloproteinases and proliferative activity. Histopathology 2004; 45: 65-72.

8. Florescu A, Mărgăritescu C, Simionescu CE, Stepan A. Immunohistochemical expression of MMP-9, TIMP-2, Ecadherin and vimentin in ameloblastomas and their implication in the local aggressive behavior of these tumors. Rom $J$ Morphol Embryol 2012; 53: 975-84.

9. Hakim SG, Kosmehl H, Sieg P, et al. Altered expression of cell-cell adhesion molecules $\beta$-catenin/E-cadherin and related Wnt-signaling pathway in sporadic and syndromal keratocystic odontogenic tumors. Clin Oral Invest 2011; 15: 321-8.

10. Kusafuka K, Hirobe K, Wato M, Tanaka A, Nakajima T. CD56 expression is associated with neuroectodermal differentiation in ameloblastomas: na immunohistochemical evaluation in comparison with odontogenic cystic lesions. Med Mol Morphol 2011; 44: 79-85.

11. Mello LA, Figueiredo AL, Ramos EA, et al. CD1a-positive Langerhans cells and their relationship with E-cadherin in ameloblastomas and keratocystic odontogenic tumors. J Oral Pathol Med 2013; 42: 454-61.

12. Siar $\mathrm{CH}, \mathrm{Ng} \mathrm{KH}$. Differential expression of transcription factors Snail, Slug, SIP1, and Twist in ameloblastoma. J Oral Pathol Med 2014; 43: 45-52.

13. De Freitas Silva BS, Yamamoto-Silva FP, Pontes HA, Pinto Júnior de dos S. E-cadherin downregulation and Twist overexpression since early stages of oral carcinogenesis. $J$ Oral Pathol Med 2014; 43: 125-31.

14. Fan CC, Wang TY, Cheng YA, et al. Expression of Ecadherin, Twist, and p53 and their prognostic value in patients with oral squamous cell carcinoma. J Cancer Res Clin Oncol 2013; 139: 1735-44.

15. Liu LK, Jiang XY, Zhou XX, Wang DM, Song XL, Jiang HB. Upregulation of vimentin and aberrant expression of Ecadherin/beta-catenin complex in oral squamous cell carcinomas: correlation with the clinicopathological features and patient outcome. Mod Pathol 2010; 23: 213-24.

16. Wang C, Liu X, Huang H, et al. Deregulation of Snai2 is associated with metastasis and poor prognosis in tongue squamous cell carcinoma. Int J Cancer 2012; 130: 2249-58.

17. Zhao D, Tang XF, Yang K, Liu JY, Ma XR. Over-expression of integrin-linked kinase correlates with aberrant expression of Snail, E-cadherin and $\mathrm{N}$-cadherin in oral squamous cell carcinoma: implications in tumor progression and metastasis. Clin Exp Metastasis 2012; 29: 957-69. 
18. Mesquita AT, Santos CR, Gomez RS, Jorge J, León JE, de Almeida OP. Central granular cell odontogenic tumor: a histopathologic and immunohistochemical study. Ann Diagn Pathol 2009; 13: 405-12.

19. Alves Pereira KM, do Amaral BA, dos Santos BR, Galvão HC, Freitas Rde A, de Souza LB. Immunohistochemical expression of E-cadherin and beta-catenin in ameloblastomas and tooth germs. Oral Surg Oral Med Oral Pathol Oral Radiol Endod 2010; 109: 425-31.

20. Yilmaz M, Christofori G. EMT, the cytoskeleton, and cancer cell invasion. Cancer Metastasis Rev 2009; 28: 15-33.

21. Nguyen PT, Kudo Y, Yoshida M, Iizuka S, Ogawa I, Takata T. N-cadherin expression is correlated with metastasis of spindle cell carcinoma of head and neck region. J Oral Pathol Med 2011; 40: 77-82.

22. DI Domenico M, Pierantoni GM, Feola A, et al. Prognostic significance of $\mathrm{N}$-Cadherin expression in oral squamous cell carcinoma. Anticancer Res 2011; 31: 4211-8.

23. Franz M, Spiegel K, Umbreit C, et al. Expression of Snail is associated with myofibroblast phenotype development in oral squamous cell carcinoma. Histochem Cell Biol 2009; 131: 651-60.

24. Zhou BP, Deng J, Xia W, et al. Dual regulation of Snail by GSK-3beta-mediated phosphorylation in control of epithelialmesenchymal transition. Nat Cell Biol 2004; 6: 931-40.

25. Wang H, Wang HS, Zhou BH, et al. Epithelial-mesenchymal transition (EMT) induced by TNF- $\alpha$ requires AKT/GSK-3 $\beta$ mediated stabilization of snail in colorectal cancer. PLoS ONE 2013; 8: e56664.

26. Barrallo-Gimeno A, Nieto MA. The Snail genes as inducers of cell movement and survival: implications in development and cancer. Development 2005; 132: 3151-61.

27. Schwock J, Bradley G, Ho JC, et al. SNAI1 expression and the mesenchymal phenotype: an immunohistochemical study performed on 46 cases of oral squamous cell carcinoma. BMC Clin Pathol 2010; 10: 1.

28. Villarejo A, Cortés-Cabrera A, Molina-Ortíz P, Portillo F, Cano A. Differential role of Snail1 and Snail2 zinc fingers in E-cadherin repression and epithelial to mesenchymal transition. J Biol Chem 2014; 289: 930-41.

29. Prasad CP, Rath G, Mathur S, Bhatnagar D, Parshad R, Ralhan R. Expression analysis of E-cadherin, Slug and GSK3beta in invasive ductal carcinoma of breast. BMC Cancer 2009; 9: 325 .

30. Fuchs BC, Fujii T, Dorfman JD, et al. Epithelial-to-mesenchymal transition and integrin-linked kinase mediate sensitivity to epidermal growth factor receptor inhibition in human hepatoma cells. Cancer Res 2008; 68: 2391-9.

31. Tsukita S, Furuse M, Itoh M. Multifunctional strands in tight junctions. Nat Rev Mol Cell Biol 2001; 2: 285-93.
32. Valcourt U, Kowanetz M, Niimi H, Heldin CH, Moustakas A. TGF-beta and the Smad signaling pathway support transcriptomic reprogramming during epithelial-mesenchymal cell transition. Mol Biol Cell 2005; 16: 1987-2002.

33. Zhang J, Cheng Q, Zhou Y, Wang Y, Chen X. Slug is a key mediator of hypoxia induced cadherin switch in HNSCC: correlations with poor prognosis. Oral Oncol 2013; 49: 104350 .

34. Zhu LF, Hu Y, Yang CC, et al. Snail overexpression induces an epithelial to mesenchymal transition and cancer stem celllike properties in SCC9 cells. Lab Invest 2012; 92: 744-52.

35. Bolós V, Peinado H, Pérez-Moreno MA, Fraga MF, Esteller M, Cano A. The transcription factor Slug represses E-cadherin expression and induces epithelial to mesenchymal transitions: a comparison with Snail and E47 repressors. J Cell Sci 2003; 116(Pt 3): 499-511.

36. Hajra KM, Chen DY, Fearon ER. The SLUG zinc-finger protein represses E-cadherin in breast cancer. Cancer Res 2002; 62: 1613-8.

37. Alaeddini M, Mostafaloo E, Mirmohammadkhani O, Eshghyar $\mathrm{N}$, Etemad-Moghadam S. Exploring the concept of "inflammatory angiogenesis" in keratocystic odontogenic tumor. Med Oral Patol Oral Cir Bucal 2013; 18: e241-5.

38. De Paula AM, Carvalhais JN, Domingues MG, Barreto DC, Mesquita RA. Cell proliferation markers in the odontogenic keratocyst: effect of inflammation. J Oral Pathol Med 2000; 29: $477-82$.

39. Kaplan I, Hirshberg A. The correlation between epithelial cell proliferation and inflammation in odontogenic keratocyst. Oral Oncol 2004; 40: 985-91.

40. Singh HP, Nayar A, Raj A, Kumar P. Are all odontogenic keratocysts keratocystic odontogenic tumors? Correlation between imaging features and epithelial cell proliferation $J$ Clin Imaging Sci 2012; 3: 3.

41. Dos Santos JN, Oliveira GQ, Gurgel CA, et al. Altered expression of cytokeratins in primary, recurrent and syndrome keratocystic odontogenic tumors. J Mol Histol 2009; 40: 26975 .

42. Kume K, Haraguchi M, Hijioka $\mathrm{H}$, et al. The transcription factor Snail enhanced the degradation of E-cadherin and desmoglein 2 in oral squamous cell carcinoma cells. Biochem Biophys Res Commun 2013; 430: 889-94.

43. Gasparotto D, Polesel J, Marzotto A, et al. Overexpression of TWIST2 correlates with poor prognosis in head and neck squamous cell carcinomas. Oncotarget 2011; 2: 1165-75.

\section{Conflict of interest}

All authors have declared no conflict of interests. 